\title{
Multilevel Ordinal Response Modeling of Trend of Breastfeeding Initiation
}

\author{
${ }^{1}$ Waheed Babatunde Yahya and ${ }^{2}$ Samson Babatunde Adebayo \\ ${ }^{1}$ Department of Statistics, Faculty of Science, University of Ilorin, P.M.B. 1515, Ilorin, Nigeria \\ ${ }^{2}$ Research and Evaluation Division, Society for Family Health, P.M.B. 5116 Wuse, Abuja, Nigeria
}

Received 2012-06-23, Revised 2012-06-28; Accepted 2013-07-20

\begin{abstract}
The amount of health benefits derived from breastfeeding is influenced by age of the child at initiation of the first breast milk, the duration and intensity of breastfeeding and age at which the child is introduced to supplementary foods and other liquids. In this study, the general trend of timing of breastfeeding initiation among nursing mothers in Nigeria between 1990 and 2003 is examined. The timing of initiation of the first breast milk to a child by her mother is measured in a three-level ordinal scale (immediately, within $24 \mathrm{~h}$ and days after birth) and the impacts of some socio-economic and maternal factors on this are determined. Results from this study revealed a significant improvement in the trend of early initiation of breast milk among Nigeria mothers between 1990 and 2003 ( $\mathrm{p}<0.0001)$. Mother's age at birth, her educational attainment, baby's deliveries at hospitals and mothers' domiciling in urban areas contributed positively to early initiation of the first breast milk to babies by Nigerian nursing mothers $(p<0.05)$. In the contrary however, delivery through caesarean operation and the current birth being the first delivery by a mother are both found to militate against early initiation of breastfeeding in Nigeria $(p<0.05)$. Three waves of national data from Nigerian Demographic and Health Surveys for 1990, 1999 and 2003 were employed in the study.
\end{abstract}

Keywords: Breastfeeding Initiation, Nigeria Demographic and Health Surveys (NDHS), Generalized Ordinal Logistic Regression (GOLR), Ordinal Logistic Regression (OLR), Odds Ratios (OR)

\section{INTRODUCTION}

Early introduction of breast milk to newly-born children immediately after delivery has been shown in many studies to be capable of giving the children the required immunity to diseases through mother's antibodies and this in turn, lowers the risks of early childhood deaths (Ogra and Dayton, 1979; Goldman et al., 1990; Clemens et al., 1999; Adebayo, 2004; Kramer and Kakuma, 2004; Edmond et al., 2006). This is largely due to the possibility of ingesting maternal colostrum into the children few hours after parturition. The colostrum is a liquid mixture that is rich in protein, sugar, vitamins, minerals and antibodies which a child needs to facilitate his/her growth and survivorship. Some other health benefits derivable from feeding a child with early breast milk have been reported by Feachem and Koblinsky
(1984) and Jason et al. (1984). In their different studies, they reported, among other things, that early breastfeeding of infants reduces the risk of having diarrhoea which is a major cause of infant and childhood death in sub-Sahara African and other developing countries. In a related study, Clemens et al. (1999) found that early initiation of breast milk actually reduces the risk of diarrhoea among rural Egyptian children.

Literature has reported that successful timely breastfeeding largely depends on maternal related factors such as mother's age at the birth of the child, mother's health and her educational status (Dubois and Girard, 2003; Lande et al., 2003; Scott et al., 2006) as well as some other socio-economic factors. However, studies on timing of breastfeeding initiation that monitor the trend and consider the hierarchical nature of data collection are scarcely available, especially for Nigeria. The study here Ilorin, Nigeria 
therefore is intended to explore the general trend of timing of initiation of the first breast milk to children in Nigeria over time and identifying those socio-demographic and maternal factors that are determinants of timing of breastfeeding initiation among Nigeria mothers. The impacts of some of the identified maternal related factors on timing of breastfeeding initiation shall also be examined.

The data employed for this study are from the three waves of the Nigeria Demographic and Health Surveys (NDHS) for 1990, 1999 and 2003 which are national population based surveys conducted through a multistage sampling technique. The surveys included women of reproductive ages 15-49 years and men age 15-59 years. For detailed description of survey methodology, NPC (2000; 2004). Child recode data of the surveys were used for all analyses.

The principal objective of the Nigeria demographic and health surveys is to provide current and reliable data on fertility and family planning behaviour, child mortality, children's nutritional status, the utilization of maternal and child health services as well as knowledge and attitudes towards HIV/AIDS.

Apart from fertility and mortality variables, information about the timing of initiation of breastfeeding by women of reproductive age is also available in the data. Traditional statistical techniques assume that individual observations (responses) are independent from one another. However, due to the hierarchical nature through which these data were collected, it is sometimes appropriate to assume that responses from individuals that are within the same clusters might be correlated and those in different clusters are uncorrelated. Therefore, breastfeeding attitudes of respondents (nursing mothers) that belong to the same cluster are assumed to be correlated, but uncorrelated between different clusters. Hence, a multilevel Generalized Ordinal Logistic Regression (GOLR) approach that would account for 'within cluster' correlation is used to monitor the trend of early breastfeeding behaviour of nursing mothers and explore the possible relationships between timing of breastfeeding initiation and its determinants within the hierarchical nature of the data. Findings from this study will provide information that will assist policy makers in assessing impact of previous interventions on improving timing of breastfeeding initiation and attitude about child breastfeeding among child-bearing women of reproductive age in Nigeria. These will further assist health administrators, policy makers and government in designing appropriate interventions that can assist on improving the breastfeeding attitude of nursing mothers in Nigeria.

\subsection{Data Descriptions}

The NDHS data for 1990, 1999 and 2003 contained socio-demographic and maternal related responses from 7,902, 3,552 and 5,138 mothers of reproductive ages respectively. Thus, a total of 16,592 mothers are involved in the three NDHS data sets combined. Out of this figure complete information is only available for 12,774 respondents and as a result, the remaining 3,818 respondents with incomplete information as required in this study were excluded from the study. Therefore, the analysis and results reported here are based on 12,774 respondents. The mean age of mothers in the study is 26.27 years with a standard deviation of 6.86 . The minimum and maximum ages of mothers involved in this study are 11 and 49 years respectively.

Similar to Adebayo (2004), a question on when child was put to breast after birth was used to determine the child's age at breastfeeding initiation. The age at which a child was given the first breast milk plays a vital role in determining his/her health status as well as that of his/her mother. Early initiation of breastfeeding could help mother's uterus to retract, which can reduce postpartum blood loss which is a major complication after birth that might result into maternal mortality, Adebayo (2004). Thus, the child's age at which he/she was given the first breast milk determines the timing of his/her breastfeeding initiation. In this study, timing of breastfeeding initiation was measured in the following three-level categorical ordinal scale: 1 if 'Immediate' (i.e., if timing of initial breastfeeding is less than 1 hour after birth), 2 if 'delayed' (i.e., if timing of initial breastfeeding is 1 hour or more but less than $24 \mathrm{~h}$ after birth), 3 if 'late' (i.e., if timing of initial breastfeeding is $24 \mathrm{~h}$ or more after birth).

Apart from timing of breastfeeding initiation which is the response variable here, information on the following independent variables was also available in the data and they were therefore included in data analysis. These are mother's age at birth (mab) and mother's level of educational attainment which is categorised into 'no education' 'primary', 'secondary' and 'higher' educational status with no education being the reference category. Others are child's sex, locality (urban or rural) where mother domiciled at the birth of the child, method of delivery (caesarean or normal), place of delivery (homes or hospitals) (Homes include mothers' homes and other traditional delivery homes while hospitals include government and private hospitals, health centres, health posts, clinics, as well as other public or private health services centres) and type of child born (single or multiple) with male, rural, normal, home and single being the respective reference categories. 
Waheed Babatunde Yahya and Samson Babatunde Adebayo / American Journal of Biostatistics 3 (1): 1-10, 2013

Table 1. Frequency (percentage in parenthesis) distribution of determinants of breastfeeding initiation across the three levels of breastfeeding initiation periods for 12,774 surveyed samples

\begin{tabular}{|c|c|c|c|c|c|}
\hline \multirow[b]{2}{*}{ Determinants (Factors) } & \multirow[b]{2}{*}{ Factors' levels } & \multicolumn{3}{|c|}{ Timing of breastfeeding initiation } & \multirow[b]{2}{*}{ Total } \\
\hline & & Immediate (1) & Delayed (2) & Late (3) & \\
\hline \multirow{3}{*}{ Child's Sex } & & $4,347(34.03)$ & $3,738(29.26)$ & $4,689(36.71)$ & $12,774(100 \%)$ \\
\hline & Male & $2,164(33.68)$ & $1,858(28.92)$ & $2,403(37.40)$ & $6,425(50.30)$ \\
\hline & Female & $2,183(34.38)$ & $1,880(29.61)$ & $2,286(36.01)$ & $6,349(49.70)$ \\
\hline \multirow{4}{*}{$\begin{array}{l}\text { Mother's educational } \\
\text { status }\end{array}$} & No Education & $2,278(33.25)$ & $1,575(22.99)$ & $2,998(43.76)$ & $6,851(53.63)$ \\
\hline & Primary & $1,104(34.79)$ & $1,110(34.98)$ & $959(30.23)$ & $3,173(24.84)$ \\
\hline & Secondary & $807(33.71)$ & $927(38.72)$ & $660(27.57)$ & $2,394(18.74)$ \\
\hline & Higher & $158(55.38)$ & $126(35.39)$ & $72(20.22)$ & $356(2.78)$ \\
\hline \multirow[t]{2}{*}{ Locality } & Rural & $2,892(33.97)$ & $2,261(26.56)$ & $3,361(39.48)$ & $8,514(66.65)$ \\
\hline & Urban & $1,455(34.15)$ & $1,477(34.67)$ & $1,328(31.17)$ & $4,260(33.35)$ \\
\hline \multirow[t]{2}{*}{ Place of delivery } & Homes & $2,702(33.43)$ & $1,952(24.15)$ & $3,428(42.42)$ & $8,082(63.27)$ \\
\hline & Hospitals & $1,645(35.06)$ & $1,786(38.06)$ & $1,261(26.88)$ & $4,692(36.73)$ \\
\hline \multirow[t]{2}{*}{ Method of delivery } & Normal & $4,237(34.03)$ & $3,648(29.30)$ & 4,565 (36.67) & $12,450(97.46)$ \\
\hline & Caesarean & $110(33.95)$ & $90(27.78)$ & $124(38.27)$ & $324(2.54)$ \\
\hline \multirow[t]{2}{*}{ Child type } & Single & $4,208(33.99)$ & $3,611(29.17)$ & $4,560(36.84)$ & $12,379(98.91)$ \\
\hline & Twin/Multiple & $139(349)$ & $127(32.15)$ & $129(32.66)$ & $395(3.09)$ \\
\hline \multirow{6}{*}{$\begin{array}{l}\text { Mother's age at birth } \\
\text { (mab) }\end{array}$} & $15-19$ years & $654(31.46)$ & $520(25.01)$ & $905(43.53)$ & $2,079(16.27)$ \\
\hline & 20-24 years & $1,150(34.13)$ & $989(29.36)$ & $1,230(36.51)$ & $3,369(26.37)$ \\
\hline & 25-29 years & $1,186(35.99)$ & $968(29.38)$ & $1,141(34.63)$ & $3,295(25.79)$ \\
\hline & $30-34$ years & $707(34.06)$ & $646(31.12)$ & $723(34.83)$ & $2,076(16.25)$ \\
\hline & $35-39$ years & $454(35.72)$ & $403(31.71)$ & $414(32.57)$ & $1,271(9.95)$ \\
\hline & $\geq 40$ years & $142(30.28)$ & $161(34.33)$ & $166(35.39)$ & $469(3.67)$ \\
\hline \multirow[t]{3}{*}{ Birth order } & Others & $1,644(34.73)$ & $1,387(29.30)$ & $1,703(35.97)$ & $4,734(37.06)$ \\
\hline & $1^{\text {st }}$ born & $726(29.83)$ & $721(29.62)$ & $987(40.55)$ & $2,434(19.05)$ \\
\hline & $2^{\text {nd }}$ to $4^{\text {th }}$ born & $1,977(357)$ & $1,630(29.08)$ & $1,999(35.66)$ & $5,606(43.89)$ \\
\hline
\end{tabular}

We also included birth order that indicates whether the current child is the first or is in the second or higher order of births to a mother (first being the reference category). The distributions of various sociodemographic and biological features of 12,774 mothers involved in this study as well as those of their children are presented in the last column of Table 1.

To be able to monitor trend of early breastfeeding behaviour of nursing mothers, two dummy variables were created for years of study (1990-2003) with 1990 being the reference category. This provides opportunity to compare levels of breastfeeding initiation in 1999 with 1990 and 2003 with 1990.

The last predictor variable considered is parity which indicates the total number of live births already had by a mother including the current child. As employed in many studies (Dubois and Girard, 2003; Lande et al., 2003; Scott et al., 2006), we categorized mother's age at birth of the child into six using class interval of five. This yielded the following classes of mother's age (in years) as used in this study: 15-19, $20-24,25-29,30-34,35-39$ and $\geq 40$.

\section{MATERIALS AND METHODS}

As earlier reported, the outcome variable of interest (timing of initiation of breastfeeding) is measured on three ordinal levels of immediate, delayed and late initiation of breastfeeding. Therefore, for any $i^{\text {th }}$ subject in the sample, the response variable $Y_{i}, i=1, \ldots, n$, is defined by Equation 1 :

$Y_{i}=\left\{\begin{array}{l}1: \text { if time if breasfeeding initiation is "immediate" } \\ 2: \text { if time if breasfeeding initiation is "delayed" } \\ 3: \text { if time if breasfeeding initiation is "late" }\end{array}\right.$

Considering the form of the response variable $\mathrm{Y}_{\mathrm{i}}$ in (1) as well as the hierarchical nature of the data, a proportional odds model which is a classical form of Ordinal Logistic Regression (OLR) model was fitted. Here, all predictor variables are allowed to enter the model non-linearly. More generally, for any ordered categorical response variable $\mathrm{Y}_{\mathrm{i}}$ and vector $\mathrm{X}$ of categorical and/or metrical covariates, the OLR model is of the form Equation 2: 
Waheed Babatunde Yahya and Samson Babatunde Adebayo / American Journal of Biostatistics 3 (1): 1-10, 2013

Table 2. Results of Generalized Ordinal Logistic Regression (GOLR) model of timing of breastfeeding initiation for model 1 (ordinal level 1 versus ordinal levels 2 and 3) (Ordinal level is 1 if timing of initial breastfeeding is less than 1 hour after birth (immediate), ordinal level is 2 if timing of initial breastfeeding is $1 \mathrm{~h}$ or more but less than $24 \mathrm{~h}$ (delayed) and ordinal level is 3 if timing of initial breastfeeding is $24 \mathrm{~h}$ or more after birth (late)) showing the odds ratio, standard error, $\mathrm{p}$-value, $95 \%$ confidence intervals and the percentage change in odds ratio for unit change in the level of each of the risk factors. ${ }^{* *}$ Negative $\%$ change in Odds Ratios (OR) indicates a reduced risk of late breastfeeding initiation due to the effect of the respective factor

\begin{tabular}{|c|c|c|c|c|c|c|}
\hline Risk factors & & $\begin{array}{l}\text { Odds Ratio } \\
(\mathrm{OR})\end{array}$ & s.e. (OR) & $\mathrm{p}$-value & $\begin{array}{l}95 \% \text { C.I. } \\
\text { of OR }\end{array}$ & $\begin{array}{l}\% \text { change } \\
\text { in } \mathrm{OR}^{* *}\end{array}$ \\
\hline Child's Sex & & 0.9639 & 0.0352 & 0.314 & $(0.8973,1.0354)$ & -3.6 \\
\hline Mother's educational & Primary & 0.9570 & 0.0620 & 0.498 & $(0.8428,1.0867)$ & -4.3 \\
\hline \multirow[t]{2}{*}{ status } & Secondary & 1.0161 & 0.0789 & 0.837 & $(0.8727,1.1830)$ & 1.6 \\
\hline & Higher & 0.6535 & 0.0986 & $0.005^{*}$ & $(0.4862,0.8784)$ & -34.7 \\
\hline Locality & & 1.0165 & 0.08175 & 0.839 & $(0.8683,1.1901)$ & 1.7 \\
\hline Place of delivery & & 0.9442 & 0.0587 & 0.356 & $(0.8359,1.0665)$ & -5.6 \\
\hline Method of delivery & & 1.1828 & 0.1539 & 0.197 & $(0.9165,1.5263)$ & 18.3 \\
\hline Place of delivery $\times$ Method of delivery & & 1.0638 & 0.3521 & 0.852 & $(0.5561,2.0350)$ & 6.4 \\
\hline Child type & & 1.0264 & 0.1453 & 0.854 & $(0.7776,1.3548)$ & 2.6 \\
\hline Mothers' age at & $15-19$ years & 0.7009 & 0.1296 & 0.055 & $(0.4879,1.0069)$ & -29.9 \\
\hline \multirow[t]{5}{*}{ birth (mab) } & $20-24$ years & 0.6799 & 0.1206 & $0.030^{*}$ & $(0.4802,0.9627)$ & -32.0 \\
\hline & $25-29$ years & 0.6697 & 0.1214 & $0.027^{*}$ & $(0.4695,0.9554)$ & -33.0 \\
\hline & $30-34$ years & 0.7652 & 0.1417 & 0.149 & $(0.5323,1.1000)$ & -23.5 \\
\hline & $35-39$ years & 0.7086 & 0.1334 & 0.067 & $(0.4900,1.0248)$ & -29.1 \\
\hline & $\geq 40$ years & 0.8781 & 0.1838 & 0.535 & $(0.5825,1.3235)$ & -12.2 \\
\hline $\begin{array}{l}\text { Trend }(\text { year } 2003) \times \mathrm{mab} \\
(15-19 \text { years })\end{array}$ & & 1.3024 & 0.6331 & 0.540 & $(0.5023,3.3777)$ & 30.2 \\
\hline \multirow[t]{2}{*}{ Birth order } & 1 st born & 1.2217 & 0.1405 & 0.082 & $(0.9752,1.5305)$ & 2.2 \\
\hline & 2nd to 4 th born & 0.9902 & 0.0755 & 0.897 & $(0.8528,1.1497)$ & -0.1 \\
\hline Parity & & 0.9825 & 0.0182 & 0.340 & $(0.9474,1.0188)$ & -1.8 \\
\hline Trend (year 1999) & & 0.6541 & 0.0651 & $0.000^{*}$ & $(0.5382,0.7950)$ & -34.6 \\
\hline Trend (year 2003) & & 0.9243 & 0.0858 & 0.396 & $(0.7705,1.1088)$ & -7.6 \\
\hline Trend $($ year1999) $\times$ locality & & 0.4975 & 0.1041 & $0.001^{*}$ & $(0.3301,0.7498)$ & -50.3 \\
\hline Trend $($ year 2003$) \times$ locality & & 0.6037 & 0.1122 & $0.007^{*}$ & $(0.4195,0.8689)$ & -39.6 \\
\hline Trend $($ year2003) $\times$ primary & & 0.5870 & 0.0888 & $0.000^{*}$ & $(0.4365,0.7896)$ & -41.3 \\
\hline Trend (year2003) $\times$ secondary & & 0.5277 & 0.0980 & $0.001^{*}$ & $(0.3667,0.7594)$ & -47.2 \\
\hline Trend (year2003) $\times$ higher & & 0.2185 & 0.0849 & $0.000^{*}$ & $(0.1020,0.4681)$ & -78.2 \\
\hline
\end{tabular}

${ }^{*}$ Statistical significance is $5 \%$

Data management was done with SPSS 17.0 and Microsoft Excel packages.

$$
\operatorname{odds}\left(Y_{i} \leq j\right)=\frac{p\left(Y_{i} \leq j\right)}{1-p\left(Y_{i} \leq j\right)}=\exp \left(a_{j}+\beta^{\prime}{ }_{j} x\right)
$$

Or equivalently Equation 3:

$$
\operatorname{logit}\left(Y_{i} \leq j\right)=\operatorname{In} \frac{p\left(Y_{i} \leq j\right)}{1-p\left(Y_{i}>j\right)}=a_{j}+\beta_{j}^{\prime} x
$$

where, $p\left(Y_{i}>j\right)=1-p\left(Y_{i} \leq j\right)$. By model (2) or (3), at any ordered level $j$ of response variable $Y_{i}$, the odds $\left(Y_{i} \leq j\right)$ is computed. Therefore, the model provides the odds of being in the set of categories $Y_{i} \leq j$ versus $Y_{i}>j, j=$ $1, \ldots, \mathrm{J}-1$ with $\mathrm{J}=3$ in this study. Hence, a set of $\mathrm{J}-1$ different regression equations would be fitted simultaneously on predictor vector $\mathrm{X}$, each equation with its own estimated regression parameters. However, if the estimates of the regression parameters, except the intercept, are the same in all the J-1 fitted logit models (over the $\mathrm{j}$ ordinal levels of response variable $\mathrm{Y}_{\mathrm{i}}$ as defined in expression (3.1), that is, $\beta_{\mathrm{j}}=\beta$ in model (2) for all $\mathrm{j}$ ) this is an indication that the proportional odds (parallel regression) assumption (McCullagh, 1980) on ordinal logit model (14.2) holds. If this situation happens, it shows that the estimated J-1 odds for each of the cut-off ordinal category $\mathrm{j}$ differ only with regard to the intercept $a_{j}$. This assumption was tested for its violation or otherwise at analysis stage. However, when the logistic regression coefficients $\beta_{\mathrm{j}}$ depend on the ordinal level $j$ of categorical response variable $Y_{i}$, then, it shows that the proportional odds assumption on model 
(3.2) is violated and the appropriate statistical model, the Generalized Ordinal Logistic Regression (GOLR) model (Long and Freese, 2006), that provides separate estimates of the regression parameters $\beta_{\mathrm{j}}$ or separate odds ratios exp $\left(\beta_{\mathrm{j}}\right)$ of each of the $\mathrm{j}$ regression model, $\mathrm{j}=$ $1, \ldots, \mathrm{J}-1$ should be employed as adopted here. Most of the analyses carried out in this study were performed using STATA/SE 10.0 software.

Table 1 presents some descriptive information about the 12,774 surveyed samples in the three waves of NDHS data considered. Initiation of breastfeeding was delayed in about two-thirds of the children. The implication is that, only about a third of the respondents' children are likely to receive colostrums. As a consequence, there is a higher likelihood of early introduction of other supplements which can increase the risks of a child contracting infections that could in turn lead to infant and childhood death.

\subsection{Data Analysis}

In epidemiological literature, place of delivery, maternal educational attainment, place/locality of residence and mother's age at birth of the child among other factors, have been found to be associated with timing of breastfeeding initiation. From the descriptive statistics in Table 1, it is revealed that almost 7 out of every 10 births took place outside hospitals. Breastfeeding initiation was very late or delayed in about $70 \%$ of children from mothers with no education; while more than three quarters of children whose breastfeeding initiation was delayed or very late came from rural localities. About $70 \%$ of mothers aged 15-19 years recorded delayed or late breastfeeding initiation for their children. Significant association between all these factors and timing of breastfeeding initiation was evident through Pearson Chi-square test of bivariate association $(\mathrm{p}<0.0001)$.

In line with our proposed model (3.2), ordinal logistic regression model was fitted using the three waves of NDHS data combined. The clustering variable that indicates the hierarchical nature of the data was incorporated to enhance the robustness of the model as discussed earlier. The assumption of parallel regression assumption was tested using the Brant test (Long and Freese, 2006) and violation of this assumption was reported by this test for virtually all the predictor variables considered $(p<0.0001)$. Due to the violation of the proportional odds assumption by our data, we then fitted the GOLR model to the data.

Two different equations were fitted under the GOLR modelling since the outcome variable $\mathrm{Y}_{\mathrm{i}}$ has three ordinal levels $\mathrm{j}=1,2,3$ as defined in expression (3.1). The first equation, here called model 1 , estimated the odds of being at the lowest ordinal level $\mathrm{j}=1$ (immediate) versus the other two higher levels $\mathrm{j}=2$ (delayed) and $\mathrm{j}=3$ (late) while the second equation, model 2, estimated the odds of being at the first two ordinal response levels $\mathrm{j}=1$ (immediate) and 2 (delayed) versus the third highest level $\mathrm{j}=3$ (late). By simple interpretation, model 1 estimates the odds of initiating the first breast milk to children within the first one hour of birth $(\mathrm{j}=1)$ as compared to the odds of initiating the breast milk at any other delayed period of time after birth $(\mathrm{j}=2$ and 3$)$. On the other hand, model 2 compares the odds of initiating the first breast milk either immediately or within the first $24 \mathrm{~h}$ of birth $(\mathrm{j}=1$ and 2$)$ against the odds of initiating the breast milk after the first day of birth $(j=3)$. Therefore, model 1 models ordinal level $j=$ 1 versus $j=2$ and 3 while model 2 models ordinal levels $\mathrm{j}=1$ and 2 versus $\mathrm{j}=3$.

The results of GOLR models for models 1 and 2 are presented in Table 2 and 3 respectively. The two tables report the estimated Odds Ratios (OR), standard errors of the estimated regression parameters, the p-values to justify the significance or otherwise of each predictor variables in the model as well as the $95 \%$ confidence intervals of the estimated odds ratios. Expectedly, the violation of the proportional odds model $\left(\exp \left(\beta_{\mathrm{j}}\right) \neq \exp (\beta \forall \mathrm{j}=1,2)\right)$ is evident by remarkable differences in the estimated odds ratios by models 1 and 2 as reported in Table 2 and 3 respectively. These differences are more evident among the odds ratios that are statistically significant in Table 2 .

Furthermore, the percentage change in odds ratios for a unit change in the level of each of the risk factors is reported for each predictor variable in the last columns of Table 2 and 3. This measures the percentage increase $(+)$ or decreases (-) in the risks of being at ordinal breast feeding initiation level $\mathrm{j}$ due to the influence of the respective risk factor.

\section{RESULTS}

From the results of the estimated GOLR models in Table 2 and 3, changes in the odds ratios due to the effects of most of the risk factors are more remarkably significant in model $2(p<0.05)$ than in model 1 . This simply indicates that a better study of early breastfeeding initiation behaviours of Nigeria mothers would be better achieved by combining and comparing the first two lower ordinal levels $j=1$ and 2 (immediate 
and delayed) of timing of breastfeeding initiation against the highest level $\mathrm{j}=3$ (late) using the NDHS data. Therefore, further discussions shall centre more on the results in Table 3 of model 2 that estimated the effects of some identified socio-demographic and biological factors on initiation of the first breast milk to children within the first $24 \mathrm{~h}$ of birth $(\mathrm{j}=1$ and 2$)$ as compared to the breastfeeding initiation that took place after the first day of birth $(j=3)$.

\section{DISCUSSION}

Except for sex, parity and child's type, regression results in Table $\mathbf{3}$ generally revealed significant relationship between the three ordinal levels of timing of breastfeeding initiation and all the identified sociodemographic factors $(p<0.05)$. The contribution of each factor in the model is determined by the percentage change in its Odds Ratios (OR) as presented in the last column of Table 3. According to these results for example, a nursing mother that delivers through caesarean operation has $50 \%$ odds (risk) of delaying initiation of first breast milk to her child till a later period of $24 \mathrm{~h}$ or more after delivery $(\mathrm{p}=0.003)$. Also, a mother that just gave birth to her first child has an increase risk of about $36 \%$ of delaying feeding the child with the first breast milk till after the first day of birth $(\mathrm{p}=0.008)$ relative to initiating the first breastfeeding within the first $24 \mathrm{~h}$ of birth.

In the contrary, the results here indicated that mothers with some levels of education (primary, secondary or higher) have reduced risks of delaying initiation of breastfeeding relative to illiterate mothers $(\mathrm{OR}=0.6538$ for primary, $\mathrm{OR}=0.6587$ for secondary, $\mathrm{OR}=0.4937$ for higher with no education being the reference category; $p<0.0001$ for the three results). Similarly, a nursing mother that delivers her child at the hospital has a reduced risk of about $40 \%$ of delaying initiation of breastfeeding till after the first day of birth relative to the one that delivers at homes or elsewhere $(p<0.0001)$. Furthermore, living in urban areas is positively associated with early initiation of breastfeeding. Mothers who domiciled in urban areas (localities) as at the time they deliver their babies have reduced risk of about $14 \%$ of delaying the initiation of the first breast milk till after $24 \mathrm{~h}$ of birth. Although, this variable is only significant at an $\alpha$ level that is slightly (marginally) higher than the default of $0.05(\mathrm{p}=0.051)$.

Of specific importance to this study is the variable that measures trend of breastfeeding initiation behaviours among nursing mothers in Nigeria from which two dummies were created for the years 1999 and 2003 with year 1990 being the reference year. Results of GOLR model in Table 3 showed a significant reduction of about $43 \%$ in the odds (risk) of delaying early initiation of breastfeeding till after the first day of birth by nursing mothers in Nigeria between 1990 and 1999 while the risk reduces by about $37 \%$ between 1990 and $2003(\mathrm{p}<0.0001)$.

The interactions effects of the trend variables with some other factors in the models were examined and the results obtained revealed significant changes in the effects of some of these risk factors on timing of breastfeeding initiation over time. For instance in Table 2 and 3, the interaction of the trend variable for the year 2003 with mother's educational attainment showed that between the year 1990 (the reference year) and year 2003, the risk that mothers with some level of educational attainment will delay early initiation of breastfeeding beyond the first $24 \mathrm{~h}$ of birth decreases significantly over time.

This is evidently clear by the results in Table $\mathbf{3}$ in which the OR $=0.5106(\mathrm{p}<0.0001)$ for primary, OR $=$ $0.3795(\mathrm{p}<0.0001)$ for secondary and $\mathrm{OR}=0.3688(\mathrm{p}=$ 0.011 ) for mothers with higher educational status. This translates to reduced risks of about 49,62 and $63 \%$ respectively of delaying initiation of breastfeeding beyond the first $24 \mathrm{~h}$ of birth between the years 1990 and 2003. Similar results are reported by model 1 in Table 2. These results are not unexpected since the general literacy level in Nigeria increases by time passage. Interestingly, mothers' educational attainment has been established here (Table 3) to contribute significantly to reduced risk of delaying early initiation of breastfeeding $(\mathrm{p}<0.0001)$.

Furthermore, from the results in Table 3, the interaction of the two trend variables for the years 1999 and 2003 with the one that represents the locality (urban or rural) where mothers domiciled at the time of delivery also showed that, from the years 1990-1999 and 19902003, the risk of delaying early initiation of breastfeeding by mothers that domiciled in urban area reduces significantly by about $40 \%(\mathrm{OR}=0.5501, \mathrm{p}=$ 0.002 for trend year 1999; $\mathrm{OR}=0.6098, \mathrm{p}=0.004$ for trend year 2003). Again, similar results are reported in Table 2 for the interaction of trends with this factor.

Similarly, the interaction between place of delivery (homes or hospitals) and delivery method (caesarean or normal delivery) in Table 3 show clearly that caesarean delivery at hospitals impacted negatively on early initiation of breastfeeding. The result indicated an increased risk of more than $300 \%$ of delaying breastfeeding initiation beyond the first $24 \mathrm{~h}$ of birth by mothers who had caesarean delivery at hospitals due to birth complications $(\mathrm{OR}=4.0873, \mathrm{p}<0.0001)$. 
Waheed Babatunde Yahya and Samson Babatunde Adebayo / American Journal of Biostatistics 3 (1): 1-10, 2013

Table 3. Results of Generalized Ordinal Logistic Regression (GOLR) model of timing of breastfeeding initiation for model 2 (ordinal levels 1 and 2 versus ordinal level 3) showing the odds ratio, standard error, p-value, 95\% confidence intervals and the percentage change in odds ratio for unit change in the level of each of the risk factors. ${ }^{* *}$ Negative $\%$ change in Odds Ratios (OR) indicates a reduced risk of late breastfeeding initiation due to the effect of the respective factor

\begin{tabular}{|c|c|c|c|c|c|c|}
\hline Risk factors & & $\begin{array}{l}\text { Odds ratio } \\
(\mathrm{OR})\end{array}$ & s.e.(OR) & p-value & $\begin{array}{l}95 \% \text { C.I. } \\
\text { of OR }\end{array}$ & $\begin{array}{l}\% \text { change } \\
\text { in } \mathrm{OR}^{* *}\end{array}$ \\
\hline Child's sex & & 0.9433 & 0.0338 & 0.104 & $(0.8793,1.0120)$ & -5.7 \\
\hline Mother's educational & Primary & 0.6538 & 0.0425 & $0.000^{*}$ & $(0.5755,0.7426)$ & -34.6 \\
\hline \multirow[t]{2}{*}{ status } & Secondary & 0.6587 & 0.0522 & $0.000^{*}$ & $(0.5640,0.7692)$ & -34.1 \\
\hline & Higher & 0.4934 & 0.0805 & $0.000^{*}$ & $(0.3584,0.6792)$ & -50.7 \\
\hline Locality & & 0.8642 & 0.0647 & 0.051 & $(0.7462,1.0009)$ & -13.6 \\
\hline Place of delivery & & 0.6025 & 0.0359 & $0.000^{*}$ & $(0.5360,0.6772)$ & -39.8 \\
\hline Method of delivery & & 1.5000 & 0.2015 & $0.003^{*}$ & $(1.1531,1.9523)$ & 50.0 \\
\hline Place of delivery $\times$ & & 4.0873 & 1.3954 & $0.000^{*}$ & $(2.0934,7.9807)$ & 308.7 \\
\hline \multicolumn{7}{|l|}{ Method of delivery } \\
\hline Child type & & 1.1001 & 0.1579 & 0.504 & $(0.8309,1.4582)$ & 10.0 \\
\hline Mothers' age at & $15-19$ years & 0.7983 & 0.1179 & 0.127 & $(0.5976,1.0664)$ & -20.2 \\
\hline \multirow[t]{5}{*}{ birth (mab) } & $20-24$ years & 0.7261 & 0.1043 & $0.026^{*}$ & $(0.5480,0.9623)$ & -27.4 \\
\hline & $25-29$ years & 0.7064 & 0.1015 & $0.016^{*}$ & $(0.5330,0.9362)$ & -29.4 \\
\hline & $30-34$ years & 0.7220 & 0.1075 & $0.029^{*}$ & $(0.5394,0.9666)$ & -27.8 \\
\hline & $35-39$ years & 0.6248 & 0.9877 & $0.003^{*}$ & $(0.4583,0.8517)$ & -37.5 \\
\hline & $\geq 40$ years & 0.6646 & 0.1149 & $0.018^{*}$ & $(0.4736,0.9325)$ & -33.5 \\
\hline $\begin{array}{l}\text { Trend }(\text { year } 2003) \times \\
(15-19 \text { years })\end{array}$ & & 2.3087 & 0.7948 & $0.015^{*}$ & $(1.1758,4.5333)$ & 130.9 \\
\hline \multirow[t]{2}{*}{ mab Birth order } & 1st born & 1.3616 & 0.1572 & $0.008^{*}$ & $(1.0858,1.7073)$ & 36.2 \\
\hline & 2nd-4th born & 1.0500 & 0.0819 & 0.531 & $(0.9013,1.2234)$ & 5.0 \\
\hline Parity & & 0.9964 & 0.0188 & 0.531 & $(0.9602,1.0339)$ & -0.4 \\
\hline Trend (year 1999) & & 0.5696 & 0.0554 & $0.000^{*}$ & $(0.5214,0.7537)$ & -43.0 \\
\hline Trend (year 2003) & & 0.6269 & 0.0589 & $0.000^{*}$ & $(0.5214,0.7537)$ & -37.3 \\
\hline Trend (year1999) × locality & & 0.5501 & 0.1055 & $0.002^{*}$ & $(0.3777,0.8012)$ & -45.0 \\
\hline Trend (year2003) × locality & & 0.6098 & 0.1057 & $0.004^{*}$ & $(0.4342,0.8565)$ & -39.0 \\
\hline Trend (year2003) $\times$ primary & & 0.5106 & 0.0779 & $0.000^{*}$ & $(0.3786,0.6886)$ & -48.9 \\
\hline Trend (year2003) $\times$ secondary & & 0.3795 & 0.0689 & $0.000^{*}$ & $(0.2658,0.5418)$ & -62.1 \\
\hline Trend $($ year2003) $\times$ higher & & 0.3688 & 0.1446 & $0.011^{*}$ & $(0.1710,0.7954)$ & -63.1 \\
\hline
\end{tabular}

${ }^{*}$; Statistical significance is $5 \%$

As for mother's age at birth of the child (mab), the risk of delaying breastfeeding initiation reduces as mothers get older in age as shown by the results in Table 3. For instance, the risk of delaying early breastfeeding till after the first $24 \mathrm{~h}$ of birth by young mothers aged between 20-24 years reduces by about $27 \%$ compared to a reduced risk of about $34 \%$ due to presumably experienced and old mothers of age 40 years and above. However, a reduced risk of delaying early initiation of breastfeeding by mothers of tender ages between 15-19 years is unexpected, as indicated by the result in Table 3 . It is therefore not surprising that the odds ratio of 0.7983 (a reduced risk of about 20\%) due to this age group of mothers is not statistically significant $(p=0.127)$. Nonetheless, the true impact of this age group of mothers (15-19 years) on the timing of breast feeding initiation was captured by the interaction of mother's age at birth for age group 15-19 years and the trend variable for year 2003. The results on Table 3 showed that, over time passage, precisely from $1990-2003$, there is about $130 \%$ increased risk of delaying initiation of breastfeeding beyond $24 \mathrm{~h}$ of birth by mothers of tender age group between 15-19 years $(\mathrm{OR}=2.3087, \mathrm{p}=0.015)$. This shows that the effects of nursing mothers of tender age on timing of breastfeeding initiation can be felt over a fairly longer period of time.

More generally, the impact of each of the identified risk factors on breastfeeding behaviours of mothers in Nigeria can be better explained through their estimated prediction probabilities at the three levels of timing of breastfeeding initiation as presented on Table 4. This is intended to provide an understandable metric measure that will describe the importance of each risk factor identified in the model. The results presented on Table 4 are only for the risk factors that showed significance association with the three levels of timing of breastfeeding initiation as contained in GOLR results of Table 3 for model 2. 
Waheed Babatunde Yahya and Samson Babatunde Adebayo / American Journal of Biostatistics 3 (1): 1-10, 2013

Table 4. Estimated prediction probabilities, $\hat{p}\left(Y_{i}=j \mid x_{k}\right)$ of each risk factor at the three ordinal levels of timing of breastfeeding initiation

\begin{tabular}{|c|c|c|c|c|}
\hline \multirow[b]{2}{*}{ Risk factors } & \multirow[b]{2}{*}{ Risk factors' levels } & \multicolumn{3}{|c|}{ Estimated predicted probabilities } \\
\hline & & Immediate & Delayed & Late \\
\hline \multirow[t]{2}{*}{ Primary } & 0 (no education) & 0.2814 & 0.3537 & 0.3649 \\
\hline & 1 (primary education) & 0.3958 & 0.3485 & 0.2556 \\
\hline \multirow[t]{2}{*}{ Secondary } & 0 (no education) & 0.2913 & 0.3549 & 0.3537 \\
\hline & 1 (secondary education) & 0.3729 & 0.3526 & 0.2745 \\
\hline \multirow[t]{2}{*}{ Higher } & 0 (no education) & 0.3010 & 0.3558 & 0.3732 \\
\hline & 1 (higher education) & 0.5049 & 0.3143 & 0.1808 \\
\hline \multirow[t]{2}{*}{ Locality } & 0 (Rural) & 0.2955 & 0.3554 & 0.3738 \\
\hline & 1 (Urban) & 0.3546 & 0.3464 & 0.2997 \\
\hline \multirow[t]{2}{*}{ Place of delivery } & 0 (Homes) & 0.2698 & 0.2977 & 0.3902 \\
\hline & 1 (Hospitals) & 0.3930 & 0.2992 & 0.2579 \\
\hline \multirow[t]{2}{*}{ Method of delivery } & 0 (Normal) & 0.3088 & 0.2994 & 0.3663 \\
\hline & 1 (Caesarean) & 0.2810 & 0.3209 & 0.4884 \\
\hline \multirow[t]{2}{*}{ Trend (year 1999) } & 0 (reference year 1990) & 0.3071 & 0.2971 & 0.3958 \\
\hline & 1 (year 1999) & 0.3683 & 0.2941 & 0.2875 \\
\hline \multirow[t]{2}{*}{ Trend (year 2003) } & 0 (reference year 1990) & 0.3120 & 0.2977 & 0.3903 \\
\hline & 1 (year 2003) & 0.4184 & 0.2993 & 0.3324 \\
\hline \multirow[t]{2}{*}{ Birth order } & 0 (others) & 0.3433 & 0.2997 & 0.3570 \\
\hline & 1 (1st born) & 0.2907 & 0.2947 & 0.4146 \\
\hline
\end{tabular}

From Table 4, the predicted probability, $\hat{p}\left(Y_{i}=j \mid x_{k}\right)$ of feeding a child with the first breast milk immediately after birth given that the delivery method is by caesarean is relatively smaller $(0.28)$ than higher predicted probabilities of 0.32 and 0.49 of breastfeeding the child at any delayed periods within $24 \mathrm{~h}$ and after the first $24 \mathrm{~h}$ of birth respectively. This pattern of prediction probabilities is not unexpected since mothers who gave birth through caesarean already have delivery complications and the chance that she would be strong enough to initiate the first breast milk to her baby immediately after birth will surely be smaller. Similarly, an inexperienced nursing mother who just had her first child has a smaller chance of about $29 \%$ of initiating the first breast milk to her child. Instead, she has a higher chance of about $41 \%$ of delaying initiating the first breast milk to her child till after the first $24 \mathrm{~h}$ of birth.

Also, a mother with some level of educational attainment has about $40 \%$ chance of initiating the first breast milk to her child immediately after birth compared to illiterate mothers with a relatively smaller chance of about $28 \%$ of early breastfeeding initiation as shown in Table 4 for the three levels of educational attainment of primary, secondary and higher education. The simple point here is that educated mothers have higher chance of initiating the first breast milk to their children earlier than their uneducated counterparts.
In the same manner, nursing mothers who gave birth at hospitals have a better chance of about $40 \%$ of initiating the first breast milk to their babies probably due to proper care and assistance received by such mothers at hospitals relative to mothers who delivered at homes with a smaller chance of about $27 \%$ of successful early initiation of breastfeeding. Also, mothers that domiciled in urban areas till the period of delivery have higher chance of about $35 \%$ of initiating the first breast milk compare to mothers that live in the rural areas with a relatively smaller chance of about $30 \%$ of early breastfeeding initiation.

For the trend variables, the predicted probability of initiating the first breast milk immediately after birth by mothers increases from around 0.31 in 1990 (the reference year) to 0.37 in 1999 and to 0.42 in 2003 as mothers supposedly become more enlightened over passage of time. This can be seen as the effect of improved literacy level among nursing mothers in Nigeria over time.

The predicted probabilities of timely initiation of breastfeeding by mothers of various age groups are presented in Table 5. It can be easily observed from the table that mothers of all age groups have relatively higher probabilities of initiating breast milk immediately after birth. In other words, the probabilities of immediate, delay and late initiation of breastfeeding by mothers monotonically decreases within each age group of mothers. 


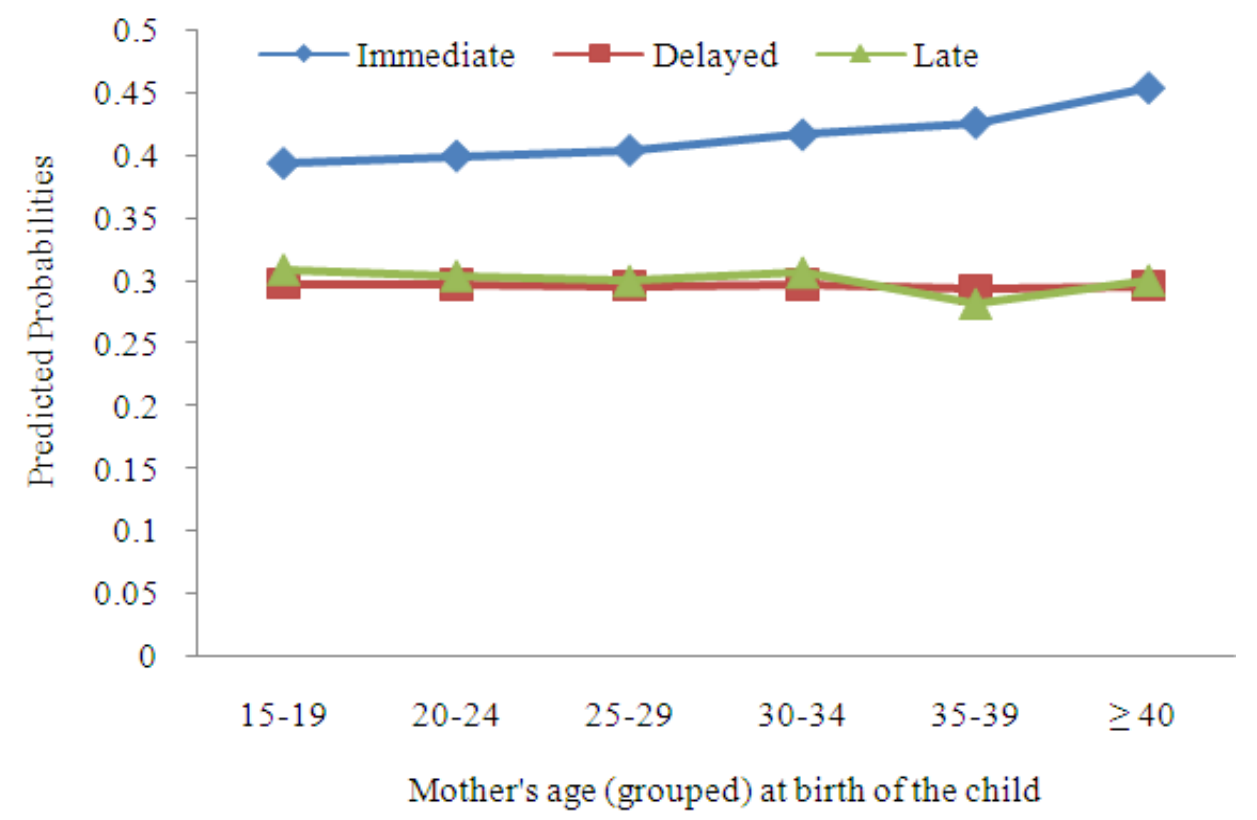

Fig. 1. Graph of predicted probabilities of initiating breastfeeding immediately after birth by mothers

Table 5. Estimated prediction probabilities, $\hat{p}\left(Y_{i}=j \mid x_{k}\right)$ at the three ordered periods of breastfeeding initiation at six different age groups of mother's age at the birth of their children

\begin{tabular}{llll}
\hline & \multicolumn{3}{l}{ Estimated predicted probabilities } \\
Mothers' age & -------- \\
groups (years) & Immediate & Delayed & Late \\
\hline $15-19$ & 0.3936 & 0.2974 & 0.3090 \\
$20-24$ & 0.3993 & 0.2967 & 0.3040 \\
$25-29$ & 0.4038 & 0.2962 & 0.3000 \\
$30-34$ & 0.4162 & 0.2971 & 0.3067 \\
$35-39$ & 0.4257 & 0.2929 & 0.2814 \\
$\geq 40$ & 0.4534 & 0.2962 & 0.3004 \\
\hline
\end{tabular}

This is more pronounced at higher age group of mothers as shown in Fig. 1. For instance, at age group 35-39 years, the probabilities of immediate, delay and late initiation of breastfeeding are $0.4257,0.2929$ and 0.2814 respectively. However, results in the second column of Table 5 showed that the predicted probabilities of immediate initiation of breastfeeding after birth monotonically increases from $0.39-0.45$ as age group of mothers increases from between 15-19 years to 40 years and above. This increasing trend in prediction probabilities of immediate initiation of breastfeeding after birth with age group of mothers is clearly shown in Fig. 1 with the highest probability being at mother's age group 40 years and above. This result indicates that an experienced mother of relatively older age has a higher chance of initiating the first breast milk quicker than her younger counterparts. All these results underscore the influence of mothers' age at birth on successful timing of early breastfeeding initiation among Nigerian mothers.

\section{CONCLUSION}

The amount of health benefits derived from breastfeeding is influenced by age of the child at initiation of breastfeeding, the duration and intensity of breastfeeding and age at which the child starts to receive supplementary foods and other liquids as well as the types of supplementary liquids and foods received. Delay in breastfeeding initiation will obviously increase the chance of giving the children other (pre-lacteal) liquid supplementations that can enhance infection which in turn could lower the chance of child's survival. Lack of early initiation of breastfeeding in Nigeria can be attributable to the country's worst record in reduction of under-five mortality rates as compared to some other African countries. Findings from this study have provided information which permits opportunity of discerning the determinants of breastfeeding initiation in Nigeria.

Mother's educational status plays important role at determining the time a child is introduced to the first breast milk of the 12,774 mothers covered by this study, more than half (precisely 6,851) of them are illiterates 
who can neither read nor write. Unfortunately, about $67 \%(4,573)$ of these 6,851 illiterate mothers delayed initiation of the first breast milk to their babies beyond the first $24 \mathrm{~h}$ of births. Although, it is established here that early initiation of the first breast milk by Nigerian nursing mothers improved significantly over time. Obviously, this is not unconnected with apparent increase in literacy levels among women of reproductive age in Nigeria over time.

Not only that, the localities where mothers domiciled till the time of delivery also play significant role at determining the time they introduce the first breast milk to their babies after birth. About 2/3rd of mothers in this study, precisely 8,514 women, live in the rural areas. Among this number, only about $1 / 3 \mathrm{rd}$ of them $(2,892)$ initiated the first breast milk to their babies immediately after birth. By the results on Table 3, the risk of delaying early breastfeeding of new born babies beyond the first $24 \mathrm{~h}$ of birth reduces by about $14 \%$ among women living in urban areas relative to their counterparts living in rural areas. All these results generally showed that localities where mothers domicile have significant impacts on timing of breastfeeding initiation.

Nursing mothers that live in urban areas at the time of delivery are more likely to initiate the first breast milk to their babies earlier than their rural counterparts, probably due to accessibility of urban mothers to adequate information on the need for early initiation of breast milk and exclusive breastfeeding in general coupled with their relatively higher literacy levels. In view of this, intensive enlightenment programs are needed to sensitize prospective mothers living in the rural areas of the country on the importance and advantage of early initiation of the first breast milk to their children immediately after birth. This would tremendously help at reducing the spate of neonatal deaths in Nigeria.

Finally, pregnant women should be strongly encouraged to receive necessary antenatal treatments right from the time of conception. This will surely avail them the opportunity of receiving appropriate information on child and maternal care. All these shall immensely help at reducing several cases of complications at birth that often resulted to caesarean delivery which might in turn incapacitates mother at initiating the first breast milk to her baby immediately after child birth.

\section{REFERENCES}

Adebayo, S.B., 2004. Bayesian geoadditive modelling of breastfeeding initiation in Nigeria. J. Applied Econ., 19: 267-281. DOI: $10.1002 /$ jae. 732
Clemens, J., R.A. Elyazeed, M. Rao, S. Savarino and B.Z. Morsy et al., 1999. Early initiation of breastfeeding and the risk of infant diarrhea in rural Egypt. Pediatrics, 104: e3-e3. PMID: 10390289

Dubois, L. and M. Girard, 2003. Social inequalities in infant feeding during the first year of life. The Longitudinal Study of Child Development in Québec (LSCDQ 1998-2002). Public Health Nutr., 6: 773-783. PMID: 14641948

Edmond, K.M., C. Zandoh, M.A. Quigley, S. AmengaEtego and S. Owusu-Agyei et al., 2006. Delayed breastfeeding initiation increases risk of neonatal mortality. Pediatrics, 117: 380-386. DOI: 10.1542/peds.2005-1496

Feachem, R.G. and M.A. Koblinsky, 1984. Interventions for the control of diarrhoeal diseases among young children: Promotion of breast-feeding. Bull World Health Organ., 62: 271-291. PMID: 6610496

Goldman, A.S., R.M. Goldblum and L.A. Hanson, 1990. Anti-inflammatory systems in human milk. Adv. Exp. Med. Biol., 262: 69-76.PMID: 2181825

Jason, J.M., P. Nieburg and J.S. Marks, 1984. Mortality and infectious disease associated with infant-feeding practices in developing countries. Pediatrics, 74: 702-727. PMID: 6435089

Kramer, M.S. and R. Kakuma, 2004. The optimal duration of exclusive breastfeeding: A systematic review. Adv. Exp. Biol., 554: 63-77. PMID: 15384567

Lande, B., L. Andersen, A. Baerug, K.U. Trygg and K. Lund-Larsen et al., 2003. Infant feeding practices and associated factors in the first six months of life: The Norwegian infant nutrition survey. Acta Paediatr., 92: 152-161. PMID: 12710639

Long, J.S. and J. Freese, 2006. Regression Models for Categorical Dependent Variables using STATA. 2nd Edn., Stata Press, Texas, ISBN-10: 1597180114, pp: 527.

McCullagh, P., 1980. Regression models for ordinal data. J. Royal Statist. Soc. B, 42: 109-142.

NPC, 2000. Nigeria Demographic and Health Survey 1999. 1st Edn., National Population Commission, Nigeria, pp: 321.

NPC, 2004. Nigeria demographic and health survey, 2003. 1st Edn., National Population Commission, Nigeria, pp: 333.

Ogra, P.L. and D.H. Dayton, 1979. Immunology of Breast Milk. 1st Edn., Raven Press, New York, ISBN-10: 0890043876, pp: 284.

Scott, J.A., Binns, C.W., Oddy, W.H. and Graham, K.I., 2006. Predictors of breastfeeding duration: Evidence from a Cohort study. Pediatrics, 117: e646-e655. DOI: $10.1542 /$ peds.2005-1991 